\title{
Cobalt-Mediated Asymmetric 1,6-Alkyne Addition to Conjugated Carbonyls
}

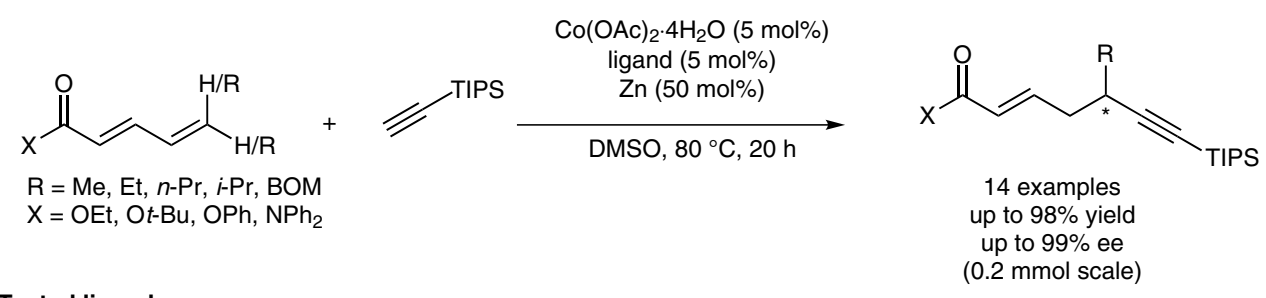

Tested ligands:<smiles>CC(P)PC(C)C(C)P</smiles>

$(S, S)$-Chiraphos<smiles>CC(CC(C)[C@H](C)Pc1ccccc1)Pc1ccccc1</smiles>

$(S, S)$-BDPP

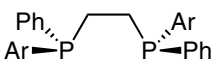

$\mathrm{Ar}=o$-methoxyphenyl $(R, R)$-DIPAMP<smiles>CP(C(C)(C)C)C(C)(C)C</smiles>

$(R, R)$-Quinox $\mathrm{P}^{*}$

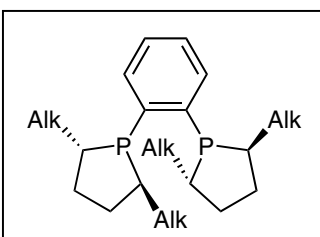

Alk =

$\operatorname{Me}(S, S)$-Me-Duphos Et $(S, S)$-Et-Duphos

Proposed catalytic cycle:

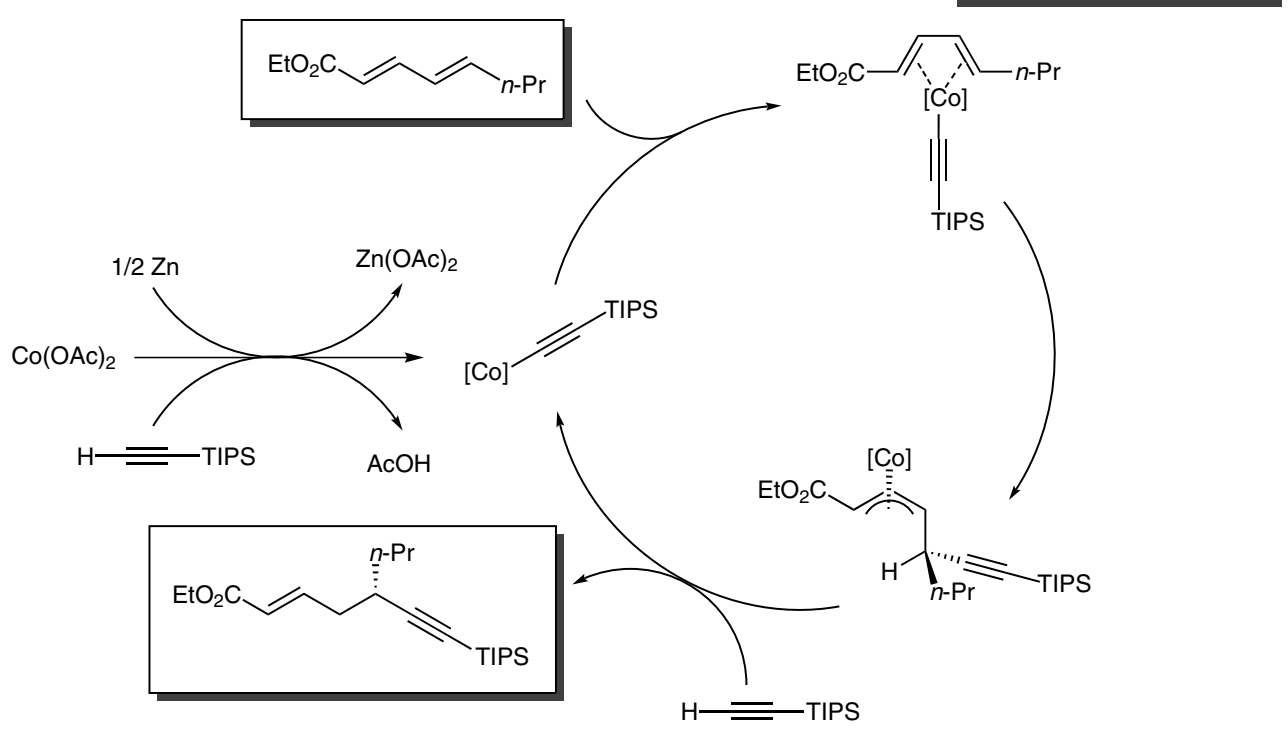

Significance: Asymmetric additions of acetylenes to conjugated $\pi$-systems have gained growing interest in recent years (Y. Watanabe et al. J. Org. Chem. 1985, 50, 565; M. Shirakura, M. Suginome Angew. Chem. Int. Ed. 2010, 49, 3827). Herein, a cobalt-catalyzed addition of TIPS-acetylene is described.

SYNFACTS Contributors: Mark Lautens, Harald Weinstabl Synfacts 2013, 9(2), 0165 Published online: 18.01.2013 DOI: 10.1055/s-0032-1317975; Reg-No.: L16512SF

\section{Category}

Metal-Catalyzed

Asymmetric

Synthesis and

Stereoselective

Reactions

\section{Key words}

asymmetric

addition

$\alpha, \beta, \gamma, \delta$-unsaturated compounds

\section{Duphos}

1,6-addition
Comment: The presented method allows the asymmetric addition of TIPS-acetylene to $\alpha, \beta, \gamma, \delta$ unsaturated carbonyl compounds with high regioand enantioselectivity. 